\title{
Evaluation of endothelial function and subclinical atherosclerosis in association with hepatitis $C$ virus in HIV-infected patients: a cross-sectional study
}

\author{
Mar Masiáa ${ }^{*}$, Sergio Padilla ${ }^{1}$, Catalina Robledano ${ }^{1}$, José M Ramos ${ }^{1}$ and Félix Gutiérrez ${ }^{1,2}$
}

\begin{abstract}
Background: Relationship of hepatitis C virus (HCV) infection with an increased risk of cardiovascular disease (CVD) in HIV-infected patients remains controversial. We evaluated endothelial function and subclinical atherosclerosis in HIV-infected patients with and without HCV.

Methods: Flow-mediated dilatation (FMD) of the brachial artery and circulating levels of cell adhesion molecules (CAM) were measured in HCV/HIV-coinfected and HIV-monoinfected patients. Subclinical atherosclerosis was assessed by carotid intima-media thickness (CIMT).

Results: 63 (31\%) HCV/HIV-coinfected and 138 (69\%) HIV-monoinfected patients were included. Median soluble vascular CAM-1 (sVCAM-1) and intercellular CAM-1 (sICAM-1) levels were significantly higher in HIV/HCV-coinfected patients ( $\mathrm{P}<0.001$ for both cases). Median (interquartile range) FMD was 6.21\% (2.86-9.62) in HCV/HIV-coinfected and 5.54\% (2.13-9.13) in HIV-monoinfected patients ( $P=0.37)$. Adjustment for variables associated with HCV and FMD disclosed similar results. FMD correlated inversely with CIMT and age. Carotid IMT did not differ between $\mathrm{HCV} / \mathrm{HIV}$-coinfected and HIV-monoinfected patients in unadjusted $(0.61$ [0.55-0.65] mm vs 0.60 [0.53-0.72] mm; $\mathrm{P}=$ 0.39) or adjusted analyses.

Conclusion: HCV infection was associated with higher levels of sICAM-1 and SVCAM-1, but no evidence of increased subclinical atherosclerosis was found when endothelial function was evaluated through FMD, or when assessing the CIMT.
\end{abstract}

\section{Background}

Relationship of hepatitis $\mathrm{C}$ virus (HCV) infection with an increased risk of cardiovascular disease (CVD) in HIVinfected patients remains controversial. While data from large cohort studies support a higher frequency of cardiovascular events in these patients $[1,2]$, other studies have shown differing results [3], and no increased subclinical atherosclerosis measured with the carotid intima-media thickness (cIMT) was found in a large cohort of HCV/ HIV-coinfected compared with HIV-monoinfected women [4].

Endothelial dysfunction (ED) is an early event in the development of atherosclerosis [5,6]. HCV/HIV-coinfection has been associated with ED in a study based in the

\footnotetext{
* Correspondence: marmasia@ya.com

${ }^{1}$ Infectious Diseases Unit, Hospital General Universitario de Elche, Alicante, Spain

Full list of author information is available at the end of the article
}

measurement of circulating cell adhesion molecules (CAM) levels [7]. Likewise, a sustained decrease in CAM levels (intercellular CAM-1 [ICAM-1] and vascular CAM-1 [VCAM-1]) has been described following therapy for $\mathrm{HCV}$ with pegylated interferon plus ribavirin [8]. At present, the non-invasive technique of choice to assess ED is flowmediated dilatation (FMD) of the brachial artery $[9,10]$, a validated test that has shown to be related to the prevalence and extent of coronary atherosclerosis [11], and to predict future cardiovascular events [12]. To date, no studies have measured brachial FMD to assess the risk of future CVD development in $\mathrm{HCV}$-infected patients.

We aimed to evaluate ED through FMD of the brachial artery and subclinical atherosclerosis through cIMT in a cohort of HIV-infected patients with and without $\mathrm{HCV}$ coinfection.
Ciomed Central

C 2011 Masiá et al; licensee BioMed Central Ltd. This is an Open Access article distributed under the terms of the Creative Commons Attribution License (http://creativecommons.org/licenses/by/2.0), which permits unrestricted use, distribution, and reproduction in any medium, provided the original work is properly cited. 


\section{Methods}

\section{Setting and inclusion/exclusion criteria}

The investigation was conducted at the HIV Outpatient Clinic of the University General Hospital of Elche, Spain. All patients visited during a four-month period (FebruaryJune 2009) were invited to participate in this crosssectional study. Eligible subjects included HIV-infected adults aged 18-75 years, whether they were coinfected with $\mathrm{HCV}$ or not, and with no changes in their antiretroviral regimen or cardiovascular risk factor therapy during the last 6 months. Exclusion criteria were active infections, negative HCV RNA or positive hepatitis B surface antigenemia in $\mathrm{HCV}$-coinfected patients, HCV previous therapy with sustained response, and pregnancy. The study was approved by the Hospital General Universitario de Elche Ethics Committee (CEIC), and all the patients gave their informed consent.

\section{Clinical and laboratory measurements}

Details were taken of age, HIV-related data, cardiovascular risk factors, lipodystrophy, and hepatitis B virus coinfection. HCV infection was defined by a positive HCV antibody assay and a confirmatory positive HCV RNA. HCV genotyping (sequencing) was performed. Dyslipidemia, diabetes and hypertension were defined by a previous diagnosis reported by the patient and/or recorded in the patients' charts, or by a current prescription of pharmacological therapy for any of such risk factors. Patients on antiretroviral therapy and/or cardiovascular risk factor therapy had to be on a stable treatment regimen for at least 6 months to be included. Lipodystrophy was defined as the presence of body-fat changes that could be clearly recognised by both the patient and the doctor. The liver fibrosis scores APRI and FIB-4 were calculated according to the proposed formulas (Table 1).

Blood samples were collected after an 8 hour overnight fast for measurement of glycaemia, total cholesterol, HDL-cholesterol, direct LDL-cholesterol, triglycerides, creatinine, CD4 cell count and HIV plasma viral load. An additional sample was processed by centrifugation. Plasma aliquots obtained were stored at $-80^{\circ} \mathrm{C}$. All frozen samples were subsequently defrosted, and plasma levels of soluble vascular cell adhesion molecule-1 (sVCAM-1) and soluble intercellular adhesion molecule-1 (sICAM-1) were measured using commercially available ELISA kits (Quantikine, R\&D Systems Europe Ltd, UK).

\section{Evaluation of endothelial function by flow-mediated dilatation of the brachial artery}

Endothelial function was evaluated by measuring FMD with a high resolution linear array vascular ultrasound transducer (Nemio XG, Toshiba Medical Systems SA) as previously described [13]. Subjects were required to be fasting and not use any tobacco-containing products for
8 hours before the study. Baseline vessel diameter was determined with the mean of three measures. Then, a forearm cuff was inflated to $240 \mathrm{~mm} \mathrm{Hg}$ for 5 minutes. Diameter of the brachial artery was measured $1 \mathrm{~min}$ after cuff deflation. FMD was calculated as the ratio of the brachial artery diameter after reactive hyperemia to baseline diameter and was expressed as a percentage of change. Nitroglycerin-mediated vasodilatation was also determined. Measurements were performed by a single sonographist blinded to the subject's information. Reproducibility was assessed in 10 healthy subjects ( 8 men, age $44 \pm 8,5$ years) who were examined by the same sonographer twice, at an interval of 2 hours. The median (interquartile range [IQR]) intraobserver intersession percentage of variation for brachial artery diameter was $2.38 \%(0-5.71)$, similar to previous studies [14].

\section{Evaluation of the carotid intima-media thickness}

For determination of the carotid IMT, B-mode high resolution ultrasound was used following a standard procedure as described previously [15]. To quantify the degree of carotid artery wall thickening, the mean of six measures performed in the posterior wall of the left and right common carotid arteries was taken. Carotid plaques were defined as a focal cIMT $\geq 1 \mathrm{~mm}$ in any of the imaged segments.

\section{Statistical analysis}

Differences in demographic and clinical characteristics between patients with and without HCV infection were assessed using the chi-squared or Fisher's exact test for categorical variables and Mann-Whitney test for continuous variables. Multivariable linear regression analyses were performed to quantify the association of $\mathrm{HCV}$ infection with the logarithm of FMD, CAM and cIMT after adjustment for potential confounding factors. Potential confounders included all variables significantly associated with hepatitis $C$ virus infection in univariate analysis, or with a trend to statistical significance $(P<0.10)$ : sex, $C$ CDC category, intravenous drug use, men who have sex with men, current protease inhibitor use, lipid-lowering therapy, smoking habit, systolic blood pressure, fasting total cholesterol and LDL-cholesterol, APRI and FIB-4. Additionally, to assess the effect of HCV on FMD values, all variables associated with FMD in univariate analysis, as well as baseline diameter of brachial artery, were also included as potential confounders in this case: age, hypertension, diabetes, and lipodystrophy. The same procedure was used to quantify the effect of the genotypes 1 and 4 versus 2 and 3 on FMD, CAM and cIMT. All P values were two-tailed. It was calculated that $70 \mathrm{HCV} /$ HIV coinfected patients and $140 \mathrm{HIV}$-monoinfected would be required to detect an absolute FMD difference between groups of $2 \%$ (standard deviation $5 \%$ ) with an 
Table 1 Characteristics of the patients with and without hepatitis $C$ coinfection

\begin{tabular}{|c|c|c|c|}
\hline Variable & $\begin{array}{l}\text { Hepatitis } \mathrm{C} \text { virus }+ \\
(\mathrm{N}=63)\end{array}$ & $\begin{array}{l}\text { Hepatitis C virus - } \\
(\mathrm{N}=138)\end{array}$ & $P$ \\
\hline Age, years (median [IQR]) & $43.7(39.4-47.0)$ & $43.5(35.6-49.5)$ & 0.55 \\
\hline Men, no. (\%) & $53(84.1)$ & $100(72.5)$ & 0.08 \\
\hline Category $\mathrm{C}$ of the CDC, no. (\%) & $13(20.6)$ & $49(35.5)$ & 0.04 \\
\hline 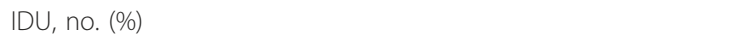 & $58(92.1)$ & $11(8.0)$ & $<0.001$ \\
\hline MSM, no. (\%) & 0 & $56(40.6)$ & $<0.001$ \\
\hline Viral load $<50$ copies/mL, no. (\%) & $44(69.8)$ & $90(65.2)$ & 0.63 \\
\hline CD4 cell count, cells/ $\mu \mathrm{L}$ (median [IQR]) & $530(280-750)$ & $495(317.5-652.5)$ & 0.86 \\
\hline On antiretroviral therapy, no. (\%) & $56(88.9)$ & $115(83.3)$ & 0.39 \\
\hline Duration of antiretroviral therapy exposure, years (median [IQR]) & $9.0(3.75-10.0)$ & $6.0(1.88-10.0)$ & 0.25 \\
\hline Non nucleoside analog-based regimen, no. (\%) & $17(27.0)$ & $53(38.7)$ & 0.11 \\
\hline Protease inhibitor-based regimen, no. (\%) & $36(57.1)$ & $58(42.3)$ & 0.07 \\
\hline Lipodystrophy ${ }^{1}$, no. (\%) & $19(30.2)$ & $47(34.1)$ & 0.63 \\
\hline Current smoker, no. (\%) & $53(84.1)$ & $71(51.4)$ & $<0.001$ \\
\hline Dyslipidemia, no. (\%) & $12(19)$ & $56(40.6)$ & 0.002 \\
\hline Lipid-lowering therapy & $5(7.9)$ & $42(30.4)$ & $<0.001$ \\
\hline Hypertension, no. (\%) & $8(12.7)$ & $29(21.0)$ & 0.17 \\
\hline Diabetes, no. (\%) & $3(4.8)$ & $14(10.1)$ & 0.28 \\
\hline Pre-existing cardiovascular disease, no. (\%) & $2(3.2)$ & $3(2.2)$ & 0.65 \\
\hline Body mass index, Kg/m2 (median [IQR]) & $24.05(21.56-27.86)$ & $25.0(21.99-28.32)$ & 0.48 \\
\hline Hepatitis B virus, no. (\%) & 0 & $4(3.0)$ & 0.30 \\
\hline Hepatitis C viral load, copies/mL (median [IQR]) & $748,056(145,564-3,204,245)$ & - & - \\
\hline APRI index (median [IQR]) & $0.67(0.39-1.29)$ & $0.22(0.18-0.31)$ & $<0.001$ \\
\hline Genotypes 1 and $4(n=37)$ & $0.67(0.40-1.11)$ & & \\
\hline Genotypes 2 and $3(n=24)$ & $0.73(0.38-1.62)$ & & $0.93^{3}$ \\
\hline FIB-4 index (median [IQR]) & $1.40(0.98-3.27)$ & $0.91(0.66-1.17)$ & $<0.001$ \\
\hline Genotypes 1 and $4(n=37)$ & $1.52(1.09-2.74)$ & & \\
\hline Genotypes 2 and $3(n=24)$ & $1.42(0.91-4.14)$ & & $0.86^{3}$ \\
\hline Waist-to-hip ratio (median [IQR]) & $0.94(0.89-0.98)$ & $0.93(0.88-0.98)$ & 0.72 \\
\hline Metabolic syndrome ${ }^{2}$, no. (\%) & $14(22.2)$ & $42(30.4)$ & 0.31 \\
\hline Framingham risk at 10 years ${ }^{4}, \%$ (median [IQR]) & $5(2-8)$ & $4(1-10)$ & 0.69 \\
\hline Systolic blood pressure, mm Hg (median [IQR]) & $122(114-133)$ & $130(118.5-142)$ & 0.006 \\
\hline Diastolic blood pressure, mm Hg (median [IQR]) & $76(69-83)$ & $79(71-85)$ & 0.21 \\
\hline Fasting total cholesterol, mg/dL (median [IQR]) & $163(146-186)$ & $185(158.8-213.3)$ & 0.001 \\
\hline Fasting LDL-cholesterol, mg/dL (median [IQR]) & $104(86-123)$ & $119.5(100-140)$ & 0.001 \\
\hline Fasting HDL-cholesterol, mg/dL (median [IQR]) & $41.2(34.5-50.2)$ & $43.5(36.9-51.2)$ & 0.56 \\
\hline Fasting triglycerides, mg/dL (median [IQR]) & $131(86-171)$ & $137.5(94.8-197.5)$ & 0.30 \\
\hline Fasting glucose, mg/dL (median [IQR]) & $87.0(81-99)$ & $87.0(80.8-97)$ & 0.93 \\
\hline VCAM-1, $\eta \mathrm{g} / \mathrm{mL}$ (median [IQR]) & $931.4(707.8-1606.5)$ & $766.6(630.3-974.5)$ & $<0.001$ \\
\hline ICAM-1, $\eta \mathrm{g} / \mathrm{mL}$ (median [IQR]) & $492.6(354.4-713.1)$ & $314.3(251.9-408.3)$ & $<0.001$ \\
\hline Baseline brachial artery diameter, cm (median [IQR]) & $4.30(3.87-4.53)$ & $4.14(3.60-4.60)$ & 0.20 \\
\hline Brachial artery FMD, \% (median [IQR]) & $6.21(2.86-9.62)$ & $5.54(2.13-9.13)$ & 0.37 \\
\hline Genotypes 1 and $4(n=37)$ & $6.78(2.01-11.80)$ & & \\
\hline Genotypes 2 and $3(n=24)$ & $5.09(3.02-8.29)$ & & $0.32^{3}$ \\
\hline Brachial artery nitroglycerine MD, \% (median [IQR]) & $18.35(15.27-25.65)$ & $19.68(12.31-24.57)$ & 0.86 \\
\hline Genotypes 1 and $4(n=37)$ & $19.44(15.50-28.16)$ & & \\
\hline Genotypes 2 and $3(n=24)$ & $18.22(11.62-22.08)$ & & $0.16^{3}$ \\
\hline Carotid IMT, mm (median [IQR]) & $0.61(0.55-0.65)$ & $0.60(0.53-0.72)$ & 0.39 \\
\hline Genotypes 1 and $4(n=37)$ & $0.59(0.52-0.65)$ & & \\
\hline
\end{tabular}


Table 1 Characteristics of the patients with and without hepatitis C coinfection (Continued)

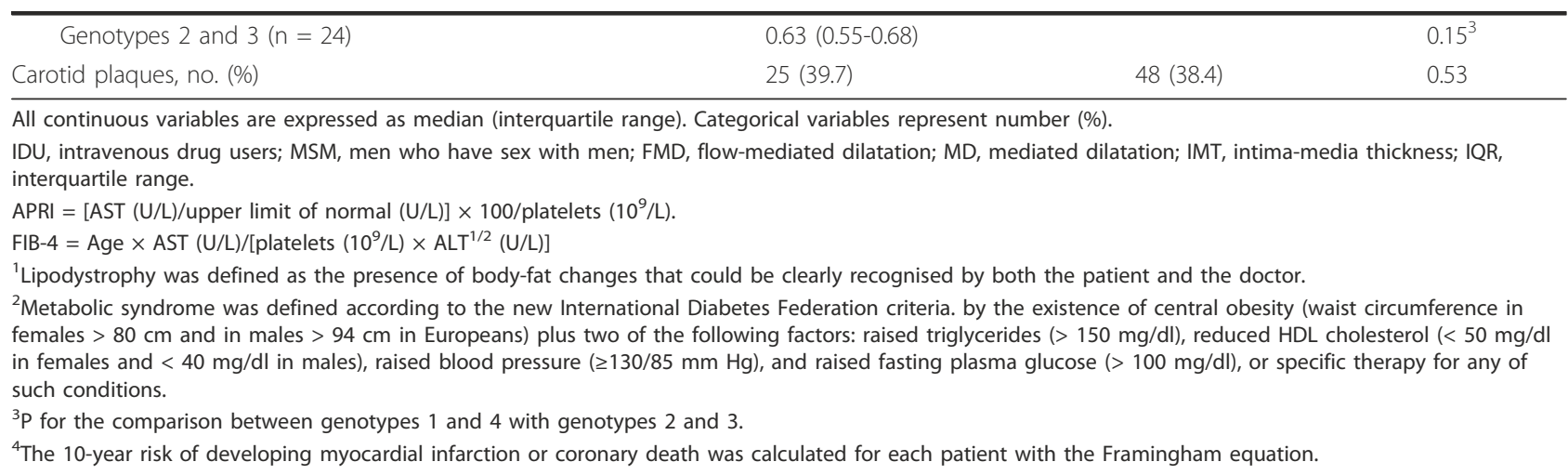

$86 \%$ statistical power, alpha 0.05 . The final statistical power of this study including 63 and 138 patients in each group was $83.8 \%$.

\section{Results}

Two hundred and fourteen patients were initially included. Of 76 patients with a positive HCV antibody assay, 5 patients were excluded because of negative $\mathrm{HCV}$ RNA, 5 patients because of previous therapy for $\mathrm{HCV}$ and a negative $\mathrm{HCV}$ viral load, and 3 patients due to $\mathrm{HCV}$ infection with positive $\mathrm{HBV}$ antigenemia, leaving 63 (31\%) patients with HCV/HIV coinfection and 138 (69\%) HIV-monoinfected patients. Characteristics of the patients are listed in Table 1. Patients with $\mathrm{HCV} / \mathrm{HIV}$ coinfection were more frequently intravenous drug users, were less likely to belong to the $C$ CDC category, and tended to receive more frequently protease inhibitors and to be men. Among traditional cardiovascular risk factors, patients with $\mathrm{HCV} / \mathrm{HIV}$ coinfection were more frequently smokers, and had a lower prevalence of dyslipidemia, lipid-lowering therapy, lower systolic blood pressure, lower total cholesterol, and LDL-cholesterol.

Median sVCAM-1 and sICAM-1 levels were significantly higher in HIV/HCV-coinfected than in HIV-monoinfected patients $(\mathrm{P}<0.001$ for both cases, Table 1$)$. When adjustment was performed for the variables associated with HCV (see Table 2), sICAM-1 levels were still 62.4\% higher in $\mathrm{HIV} / \mathrm{HCV}$ coinfected patients $(\mathrm{P}<0.001)$, and sVCAM-1 tended to be higher (33.1\%, $\mathrm{P}=0.08$ ) (Table 2 ). sICAM-1 continued to be higher in HCV-coinfected individuals when only those with an HIV viral load $<50$ copies/ml were selected (Table 2 ). There was a high correlation of sICAM-1 and sVCAM-1 with APRI (Spearman's rho $=0.42$ and 0.45 respectively) and FIB-4 Spearman's rho $=0.34$ and 0.39 respectively) fibrosis indexes $(\mathrm{P}<$ 0.001 in all cases). HCV viral load correlated with sVCAM-1 (Spearman's rho 0.36, $\mathrm{P}=0.008$ ), and to a lesser extent with sICAM-1 (Spearman's rho 0.25, $\mathrm{P}=0.07$ ). No differences between genotypes were found for SVCAM-1 or sICAM-1 in unadjusted analyses, nor after adjustment for variables associated with $\mathrm{HCV}(\mathrm{P}=0.66$ and $\mathrm{P}=0.46$ respectively).

Median (IQR) FMD was 6.21\% (2.86-9.62)\% in patients $\mathrm{HCV} / \mathrm{HIV}$-coinfected and 5.54\% (2.13-9.13)\% in HIVmonoinfected patients $(\mathrm{P}=0.37)$. No correlation was found between FMD and APRI or FIB-4 indexes. Factors associated with a lower FMD in univariate analysis were male sex $(P=0.001)$, dyslipidemia $(P=0.003)$, hypertension $(\mathrm{P}=0.02)$, diabetes $(\mathrm{P}=0.02)$, and lipodystrophy $(\mathrm{P}=$ 0.009 ). FMD correlated inversely with the cIMT (Spearman's rho $=-0.32 ; \mathrm{P}<0.001)$ and with age (Spearman's rho $=-0.23 ; \mathrm{P}=0.001)$.

Table 2 shows the effect of HCV coinfection on FMD values. After adjustment for the variables associated with $\mathrm{HCV}$ and with FMD (Table 2) and for baseline artery diameter, FMD remained not statistically different when patients $\mathrm{HCV} / \mathrm{HIV}$-coinfected and HIV-monoinfected were compared (17.23\% higher FMD values in HCV/ HIV-coinfected patients, $\mathrm{P}=0.53)$. To avoid the effect of HIV viremia on the endothelial function, the same analyses were performed only in patients with undetectable viral load (<50 copies/ml) (Table 2). FMD was again not different according to $\mathrm{HCV}$ status.

The influence of HCV genotype on FMD was also explored. FMD values did not differ between patients with genotypes $1 / 4$ and $2 / 3(\mathrm{P}=0.32)$. Adjusted analysis generated similar results $(\mathrm{P}=0.49)$.

Carotid IMT did not differ between HCV/HIV-coinfected and HIV-monoinfected patients (0.61 [0.55-0.65] $\mathrm{mm}$ vs 0.60 [0.53-0.72] mm; $\mathrm{P}=0.39$ ). After adjustment for the variables associated with $\mathrm{HCV}$, the difference between the two groups remained non-significant (Table 2). Analysis by genotypes yielded similar results, with no significant changes after adjustment (data not shown).

\section{Discussion}

We found that there was little difference in brachial FMD between $\mathrm{HCV} / \mathrm{HIV}$-coinfected and HIV-monoinfected 
Table 2 Association of HIV and HIV/HCV infection with flow-mediated dilatation, carotid intima-media thickness, and circulating levels of cell adhesion molecules

\begin{tabular}{|c|c|c|c|c|c|c|c|c|}
\hline Variable & $\begin{array}{l}\text { Mean difference in log brachial } \\
\text { artery FMD, } \%(95 \% \mathrm{Cl})\end{array}$ & $P$ & $\begin{array}{l}\text { Mean difference in log } \\
\text { carotid IMT, mm } \\
(95 \% \mathrm{Cl})\end{array}$ & $P$ & $\begin{array}{l}\text { Mean difference in log sICAM-1, } \\
\eta \mathrm{g} / \mathrm{mL}(95 \% \mathrm{Cl})\end{array}$ & $P$ & $\begin{array}{l}\text { Mean difference in log sVCAM-1, } \\
\eta \mathrm{g} / \mathrm{mL}(95 \% \mathrm{Cl})\end{array}$ & $P$ \\
\hline \multicolumn{9}{|c|}{ HIV/HCV vs. HIV } \\
\hline Unadjusted & $0.10(-0.18-0.38)$ & 0.47 & $-0.05(-0.11-0.017)$ & 0.15 & $0.36(0.22-0.50)$ & $\begin{array}{l}< \\
0.001\end{array}$ & $0.23(-0.10-0.55)$ & 0.01 \\
\hline Adjusted & $0.17(-0.33-0.68)$ & $0.50^{1}$ & $0.05(-0.05-0.16)$ & $0.27^{3}$ & $0.39(0.14-0.64)$ & $0.002^{3}$ & $0.22(0.05-0.39)$ & $0.17^{3}$ \\
\hline \multicolumn{9}{|c|}{$\begin{array}{l}\text { HIV/HCV vs. HIV } \\
\text { (patients with VL < } \\
\left.50 \mathrm{c} / \mathrm{mL}^{2}\right)^{2}\end{array}$} \\
\hline Unadjusted & $0.009(-0.33-0.34)$ & 0.96 & $-0.08(-0.16-0.003)$ & 0.06 & $0.33(0.14-0.52)$ & 0.001 & $0.17(-0.06-0.40)$ & 0.14 \\
\hline Adjusted & $0.23(-0.45-0.90)$ & $0.47^{1}$ & $0.014(-0.13-0.16)$ & $0.24^{3}$ & $0.55(0.19-0.90)$ & $0.003^{3}$ & $0.21(-0.28-0.69)$ & $0.25^{3}$ \\
\hline
\end{tabular}


patients, despite higher circulating levels of CAM among $\mathrm{HCV}$-coinfected individuals. Another surrogate marker of atherosclerosis such as the cIMT was also not different between groups. Patients with HCV/HIV coinfection from our cohort differed from the HIV-monoinfected in the prevalence of cardiovascular risk factors. HCV-coinfected individuals had less frequently dyslipidemia, had lower total and LDL-cholesterol levels, lower systolic blood pressure, and were less likely to belong to C CDC category, while they were more frequently smokers, and tended to be more often men, and to receive protease inhibitors. When all those protective and detrimental factors on cardiovascular risk were adjusted for, again not significant differences were found in endothelial function measured through brachial FMD or in the cIMT/plaque frequency between HCV/HIV-coinfected and HIVmonoinfected patients. Neither were there differences in FMD according to HCV genotype.

Our results show a pro-atherosclerotic profile in the vascular inflammation biomarkers SICAM-1 and sVCAM-1. These molecules have also been linked to hepatocellular injury, specifically sICAM-1 has been related to liver inflammatory activity and hepatocellular necrosis, and sVCAM-1 to liver fibrosis [16]. Accordingly, in our patients sICAM-1 and sVCAM-1 correlated closely with the liver fibrosis indexes APRI and FIB-4. In contrast, we did not find increased subclinical atherosclerosis when ED and cIMT were assessed in HCV-coinfected patients compared to HIV-monoinfected. These results are in agreement with those previously described with the cIMT in a cohort of HCV/HIV-coinfected women in the Women's Interagency HIV Study [4], and suggest a complex interaction among factors accounting for the risk of CVD development in $\mathrm{HCV}$-coinfected patients. Whether additional aspects associated with HCV infection, such as a more favourable lipid profile [17] or further protective factors related to $\mathrm{HCV}$ or to IDU may counteract for the proatherogenic ones or if, on the contrary, other issues such as higher plaque instability linked with inflammation $[18,19]$ or the pro-coagulant state associated with HCV $[20,21]$ may contribute to a greater incidence of ischemic events in the absence of an overt higher atherosclerotic burden, merits further research.

Although currently the test of choice for ED evaluation, FMD measurement has inherent physiological variations, and this has to be taken into account when interpreting our results. Another limitation of the study is the crosssectional design and the relatively small number of patients included; however, the sample size was in line with other studies evaluating FMD, a technically complex test, and indeed the study was powered enough to show that levels of ICAM-1 and VCAM-1 were significantly higher in $\mathrm{HCV} / \mathrm{HIV}$-coinfected patients. Additionally, this is the first study evaluating ED through FMD of the brachial artery in $\mathrm{HCV} / \mathrm{HIV}$-coinfected patients, with a representative sample of the HIV population cared for in an outpatient clinic. The inverse correlation between IMT and FMD supports the consistency of the measurements.

\section{Conclusion}

In $\mathrm{HIV}$-infected patients, $\mathrm{HCV}$ infection was associated with higher levels of ICAM-1 and VCAM-1, but no evidence of increased subclinical atherosclerosis was found when endothelial function was evaluated through brachial FMD, or when assessing the cIMT. Future prospective studies are warranted to clarify the influence of HCV infection on atherosclerotic disease in HIV-infected patients in order to optimize the management of these patients.

\section{Acknowledgements}

Supported in part by FIS (07/1268; 08/1893), FIPSE (12532/05, 12655/07), FIBELX (05/05, 18/07, 19/07, 20/07, 10/13, 10/11, 10/12), Generalitat Valenciana (085/05, 091/07, 089/07, AP-087/10), and ISCIII-RETIC RD06/0027 Red Temática Cooperativa de Investigación en SIDA (Red de Grupos 173; RIS) del FISss.

\section{Author details}

${ }^{1}$ Infectious Diseases Unit, Hospital General Universitario de Elche, Alicante, Spain. ${ }^{2}$ Department of Clinical Medicine, University Miguel Hernández, Elche, Alicante, Spain.

\section{Authors' contributions}

FG and MM conceptualized and designed the study. CR acquired data and performed the laboratory analyses. MM, FG, SP and JR analyzed and interpreted the data and results. MM and FG drafted the manuscript. All authors discussed the results and commented on the manuscript and all read and approved the final manuscript

\section{Competing interests}

The authors declare that they have no competing interests.

Received: 18 June 2011 Accepted: 3 October 2011

Published: 3 October 2011

\section{References}

1. Freiberg MS, Cheng DM, Kraemer KL, Saitz R, Kuller LH, Samet JH: The association between hepatitis $C$ infection and prevalent cardiovascular disease among HIV-infected individuals. AIDS 2007, 21:193-197.

2. Bedimo R, Westfall $A O$, Mugavero M, Saag M: Hepatitis C virus coinfection and the risk of cardiovascular disease among HIV-infected patients. HIV Med 2010, 11:462-468.

3. Weber R, Sabin C, Reiss P, de Wit S, Worm SW, Law M, Dabis F, D'Arminio Monforte A, Fontas E, El-Sadr W, Kirk O, Rickenbach M, Phillips A, Ledergerber $\mathrm{B}$, Lundgren J: HBV or HCV coinfections and risk of myocardial infarction in HIV-infected individuals: the D:A:D Cohort Study. Antivir Ther 2010, 15:1077-1086.

4. Tien PC, Schneider MF, Cole SR, Cohen MH, Glesby MJ, Lazar J, Young M, Mack W, Hodis HN, Kaplan RC: Association of hepatitis C virus and HIV infection with subclinical atherosclerosis in the women's interagency HIV study. AIDS 2009, 23:1781-1784

5. Kim JA, Montagnani M, Koh KK, Quon MJ: Reciprocal relationships between insulin resistance and endothelial dysfunction: molecular and pathophysiological mechanisms. Circulation 2006, 113:1888-1904.

6. Kashyap VS, Reil TD, Moore WS, Hoang TX, Gelabert HA, Byrns RE, Ignarro $L$, Freischlag JA: Acute arterial thrombosis causes endothelial dysfunction: a new paradigm for thrombolytic therapy. J Vasc Surg 2001, 34:323-329. 
7. de Castro IF, Micheloud D, Berenguer J, Guzmán-Fulgencio M, Catalán P, Miralles P, Alvarez E, López JC, Cosín J, Lorente R, Muñoz-Fernández MA, Resino S: Hepatitis $C$ virus infection is associated with endothelial dysfunction in HIV/hepatitis C virus coinfected patients. AIDS 2010, 24:2059-2067.

8. Masiá M, Robledano C, López N, Escolano C, Gutiérrez F: Treatment for hepatitis $C$ virus with pegylated-interferon-a plus ribavirin induces antiatherogenic effects on cardiovascular risk biomarkers in HIV-infected and uninfected patients. J Antimicrob Chemother 2011, 66:1861-1868.

9. Donald AE, Charakida M, Cole TJ, Friberg P, Chowienczyk PJ, Millasseau SC, Deanfield JE, Halcox JP: Non-invasive assessment of endothelial function: which technique? J Am Coll Cardiol 2006, 48:1846-1850.

10. Faulx MD, Wright AT, Hoit BD: Detection of endothelial dysfunction with brachial artery ultrasound scanning. Am Heart J 2003, 145:943-951.

11. Neunteufl T, Katzenschlager R, Hassan A, Klaar U, Schwarzacher S, Glogar D, Bauer P, Weidinger F: Systemic endothelial dysfunction is related to the extent and severity of coronary artery disease. Atherosclerosis 1997, 129:111-118.

12. Chan SY, Mancini GB, Kuramoto L, Schulzer M, Frohlich J, Ignaszewski A: The prognostic importance of endothelial dysfunction and carotid atheroma burden in patients with coronary artery disease. J Am Coll Cardiol 2003, 42:1037-1043.

13. Masiá M, Padilla S, García N, Jarrin I, Bernal E, López N, Hernández I, Gutiérrez F: Endothelial function is impaired in HIV-infected patients with lipodystrophy. Antivir Ther 2010, 15:101-110.

14. Juonala M, Viikari JS, Laitinen T, Marniemi J, Helenius H, Rönnemaa T, Raitakari OT: Interrelations between brachial endothelial function and carotid intima-media thickness in young adults: the cardiovascular risk in young Finns study. Circulation 2004, 110:2918-2923.

15. Masiá M, Bernal E, Padilla S, García N, Escribano JC, Martínez E, Gutiérrez F: A pilot randomized trial comparing an intensive versus a standard intervention in stable HIV-infected patients with moderate-high cardiovascular risk. J Antimicrob Chemother 2009, 64:589-598.

16. Bruno CM, Sciacca C, Cilio D, Bertino G, Marchese AE, Politi G, Chinnici L: Circulating adhesion molecules in patients with virus-related chronic diseases of the liver. World J Gastroenterol 2005, 11:4566-4569.

17. Floris-Moore M, Howard AA, Lo Y, Schoenbaum EE, Arnsten JH, Klein RS: Hepatitis $C$ infection is associated with lower lipids and high-sensitivity C-reactive protein in HIV-infected men. AIDS Patient Care STDS 2007, 21:479-491.

18. Shah PK: Inflammation and plaque vulnerability. Cardiovasc Drugs Ther 2009, 23:31-40.

19. Kiechl S, Egger G, Mayr M, Wiedermann CJ, Bonora E, Oberhollenzer F, Muggeo M, Xu Q, Wick G, Poewe W, Willeit J: Chronic infections and the risk of carotid atherosclerosis: prospective results from a large population study. Circulation 2001, 103:1064-1070.

20. Papatheodoridis GV, Papakonstantinou E, Andrioti E, Cholongitas E, Petraki K, Kontopoulou I, Hadziyannis SJ: Thrombotic risk factors and extent of liver fibrosis in chronic viral hepatitis. Gut 2003, 52:404-409.

21. Poujol-Robert A, Rosmorduc O, Serfaty L, Coulet F, Poupon R, Robert A: Genetic and acquired thrombotic factors in chronic hepatitis C. Am J Gastroenterol 2004, 99:527-531.

Pre-publication history

The pre-publication history for this paper can be accessed here: http://www.biomedcentral.com/1471-2334/11/265/prepub

doi:10.1186/1471-2334-11-265

Cite this article as: Masiá et al:: Evaluation of endothelial function and subclinical atherosclerosis in association with hepatitis C virus in HIVinfected patients: a cross-sectional study. BMC Infectious Diseases 2011 11:265.

\section{Submit your next manuscript to BioMed Central and take full advantage of:}

- Convenient online submission

- Thorough peer review

- No space constraints or color figure charges

- Immediate publication on acceptance

- Inclusion in PubMed, CAS, Scopus and Google Scholar

- Research which is freely available for redistribution 